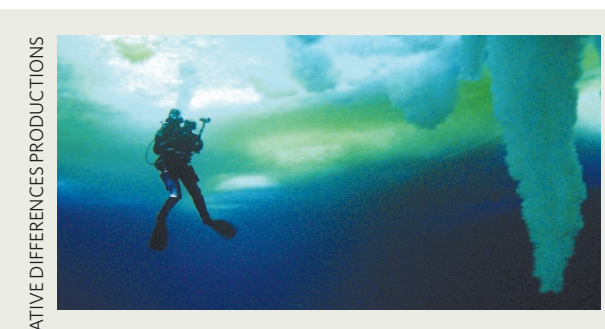

FROM POLE...

Acclaimed director Werner Herzog presents a personal view of Antarctica in his latest film, Encounters At The End of The World. He meets some of the 1,000 scientists who work at McMurdo Station, the US research headquarters on Ross Island, and muses on the beauty of the blinding landscape. Underwater shots skim the bases of ice floes and follow researchers diving for new species (pictured). The film opened last month in New York, moves to selected US cinemas during the summer and will première at the Toronto International Film Festival in Canada in September.

http://encountersfilm.com

\section{...TO POLES}

ANASA telescope features in the documentary BLAST! Film-maker Paul Devlin followed his astrophysicist brother Mark's team for 5 years as they attempted flights of the Balloonborne, Large-Aperture, Submillimeter Telescope (BLAST) in the Arctic and Antarctic. The researchers reflect on their science, philosophy and struggles to capture light from distant galaxies. The film opened in Toronto in April. It will show at film festivals worldwide, including Imagine Science in New York in October and Doc/Fest in Sheffield,

UK, in November.

www.blastthemovie.com

\section{SAVING LIVES}

The use of retroviral drugs in treating AIDS is documented by eight noted photographers in Access to Life, on show at the Corcoran Gallery in Washington DC until 20 July. Supported by Magnum Photos and the Global Fund to Fight AIDS, Tuberculosis and Malaria, it chronicles how the drugs improve the lives of 30 patients worldwide, highlighting the importance of global funding for AIDS research. The exhibition will travel to Mexico City, Paris, London, Berlin and Rome. www.corcoran.org individual and social transformation ushered in by mass-produced glass.

Armstrong's assertion that technological changes were responsible, at least in part, for profound alterations in widely different areas of human experience is part of a trend in contemporary cultural history. It recalls Lynda Nead's The Haunted Gallery (Yale University Press, 2007), which argues that the invention of moving pictures at the end of the nineteenth century influenced other forms of visual art such as painting and sculpture, and on the very act of looking. The importance of material innovations has prompted historians and cultural critics to take a much greater interest in technological developments, and offers a potential bridge between science and the humanities.

The sumptuous production quality and copious illustrations of Victorian Glassworlds make it seem at first glance just an attractive coffee-table book. In fact, Armstrong's compelling argument is complex and dense, with as much Freud and Foucault as flint or float glass. This challenging book is worth the effort, for the new window it opens on the crucially important Victorian period.

Gowan Dawson is senior lecturer in Victorian literature at the University of Leicester, University Road, Leicester LE1 7RH, UK. He is author of Darwin, Literature and Victorian Respectability.

\title{
The leaning tower of Perth
}

\section{The Cosmology Gallery \\ Gravity Discovery Centre, Gingin, \\ Australia \\ Opens 16 July 2008}

A 40-metre-high tower juts from a vast expanse of bushland. Beside it sits a futuristic dome and a huge tripod, supporting a Foucault's pendulum that traces Earth's rotation. Signs invite visitors to "walk to the end of the solar system". This is the Gravity Discovery Centre, a public outreach facility at the development site of the Australian International Gravitational Observatory. Its Cosmology Gallery opens on 16 July.

The observatory, 80 kilometres north of Perth, Western Australia, is part of an international project to search for gravity waves - moving ripples in space-time. Gravity waves were predicted by Einstein in his general theory of relativity, but have yet to be directly detected.

The new educational centre is the brainchild of scientists at the University of Western Australia. It is modelled on three buildings in Pisa, Italy: the cathedral, the baptistry and the leaning tower, where Galileo carried out his famous experiment on gravity. The tower is a triangular prism of steel that leans by $15^{\circ}$ from the vertical, farther than its namesake in Pisa, and is touted as the most deliberately leaning built structure in the world. Students climb to the top to repeat Galileo's observation that all objects fall at the same rate owing to gravity. The main visitor centre, containing exhibits about gravity and the cosmos, represents the cathedral.

The Cosmology Gallery echoes Pisa's baptistry and mixes science, art, culture and religion. Like the molecular structure of a carbon- 60 buckyball, it is composed of interlocking hexagons and pentagons. The tiled floor was designed

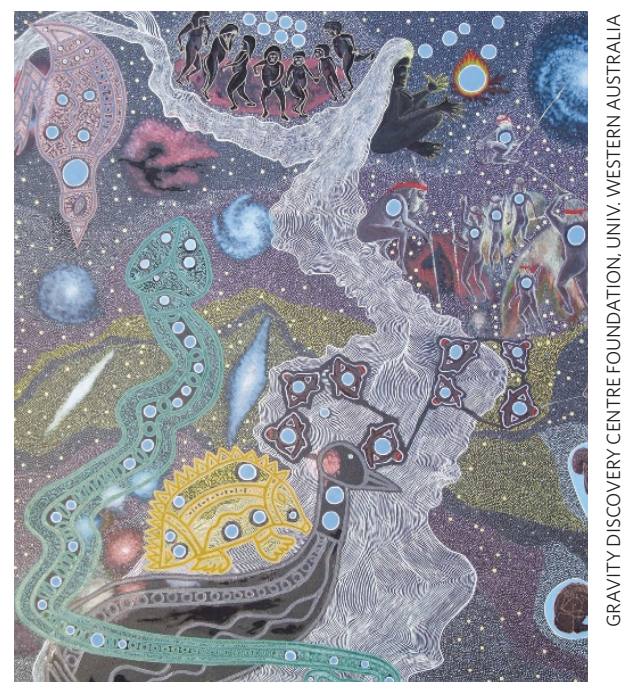

by mathematician Roger Penrose. A walkway spirals up the inside of the gallery towards higher levels and a timeline of the Universe.

Commissioned artworks explore our place in the Universe from many perspectives, including Christian, Buddhist, Hindu, Islamic and Australian Aboriginal. They include a Buddhist mandala and photographs showing re-enactments of Balinese creation legends. Bibbullmun Religion (detail, pictured), a painting by Aboriginal artist Toogarr Morrison, incorporates traditional motifs and modern images of spiral galaxies. Other paintings depict the phases of the Moon and the southern sky at night.

Just as gravity waves provide new ways to study the Universe, so the juxtaposition of scientific and cultural traditions in the gallery challenges us to broaden our thinking about cosmology.

Keith Hall is a chemist and freelance writer based in Perth, Western Australia. 